\title{
Heart Failure as a Risk Factor for Stroke
}

\author{
Woohyeun Kim, Eung Ju Kim
}

Division of Cardiology, Department of Internal Medicine, Korea University Guro Hospital, Korea University College of Medicine, Seoul, Korea

Heart failure (HF) is one of the major causes of death worldwide. Despite the high incidence of stroke in patients with $\mathrm{HF}$, there has been a controversy as to whether $\mathrm{HF}$ itself is a risk factor for stroke. Recently, there is a great deal of evidence that HF itself increases the risk of stroke. In previous studies, the benefit of warfarin for stroke prevention in patients with HF was offset by the risk of bleeding. In the era of non-vitamin $\mathrm{K}$ antagonist oral anticoagulants with low bleeding profiles, we can expect a more effective stroke prevention in patients with HF by selective anticoagulation. The purpose of this review is to describe the relationship between stroke and $\mathrm{HF}$, which could be an unconventional risk factor and a potential intervention target for stroke prevention.
Correspondence: Eung Ju Kim Division of Cardiology, Department of Internal Medicine, Korea University

Guro Hospital, Korea University College of Medicine, 148 Gurodong-ro,

Guro-gu, Seoul 08308, Korea

Tel: +82-2-2626-3022

Fax: +82-2-863-1109

E-mail:withnoel@empal.com

Received: December 1, 2017

Revised: December 26, 2017

Accepted: January 8, 2018

Keywords Heart failure; Stroke; $\mathrm{CHA}_{2} \mathrm{DS}_{2}$-VASc score

\section{Introduction}

In 2013, stroke was the second leading cause of death (11.8\% of all deaths) worldwide following ischemic heart disease (14.8\% of all deaths). ${ }^{1}$ According to the 2013 Global Burden of Disease study, the incidence, mortality, and disability-adjusted life years lost to ischemic stroke were on a declining trend from 1990 to 2013. ${ }^{2}$ However, the overall stroke burden, which is the absolute number of individuals affected by stroke or those who remained disabled from stroke, has increased in both sexes of all ages worldwide. ${ }^{1,2}$ Therefore, to reduce this overall stroke burden, the management of common modifiable lifestyle risk factors (e.g., smoking, unhealthy diet, physical inactivity, and harmful use of alcohol) is the first priority. Further, the control of other major risk factors, such as hypertension and atrial fibrillation (AF), effective treatment in the acute phase, and rehabilitation and long-term follow-up for secondary prevention are important. In addition, it is necessary to make an effort to find unconventional risk factors and control them adequately.
Heart failure (HF) is also a global major cause of death and is a rapidly growing public health issue affecting approximately 40 million individuals worldwide. ${ }^{3} \mathrm{HF}$ and stroke commonly coexist and share common risk factors, including AF. Although the risk of ischemic stroke is two to three times higher in patients with HF than in those without, ${ }_{1}^{4-6}$ whether HF itself accounts for the high risk remains unclear because most studies regarding stroke in $\mathrm{HF}$ did not differentiate between patients with and without AF nor completely adjust for the confounding variables.

In this review, we provide an up-to-date overview of the relationship between stroke and $\mathrm{HF}$, which could be an unconventional risk factor and a potential intervention target for stroke prevention. ${ }^{7-9}$

\section{What is HF and why is it important?}

\section{Definition of HF}

$\mathrm{HF}$ is a comprehensive concept that covers the chronic phase of a multitude of cardiac diseases. ${ }^{7}$ The current European Soci- 
ety of Cardiology guideline defined HF as a clinical syndrome with typical symptoms (e.g., dyspnea, ankle swelling, and fatigue) that may be accompanied by signs (e.g., elevated jugular venous pressure, pulmonary crackles, and peripheral edema) caused by a structural and/or functional cardiac abnormality, resulting in a reduced cardiac output and/or elevated intracardiac pressures at rest or during stress. ${ }^{8}$ In addition to typical symptoms or signs, early measurement of the plasma natriuretic peptide level and echocardiography are used to diagnose and classify HF. According to the guideline, HF with reduced ejection fraction (HFrEF) is defined as an ejection fraction of $<40 \%$ (previously referred to as "systolic HF"), whereas HF with preserved ejection fraction (HFpEF) is defined as an ejection fraction of $\geq 50 \%$ (previously referred to as "diastolic $\mathrm{HF}^{\prime}$ ). Patients with an ejection fraction in the range of $40 \%$ to $49 \%$ are considered to have $\mathrm{HF}$ with mid-range ejection fraction (HFmrEF).

HF typically develops as a result of several health problems related to congenital or acquired conditions and not a single illness. The major risk factors for HF are hypertension, coronary artery disease, valvular heart disease, diabetes, and AF. ${ }^{9}$

Because a failing heart cannot provide sufficient blood and oxygen to the body to ensure systemic metabolism at rest and during activity, when organ perfusion is confined to the brain, $\mathrm{HF}$ may cause cerebral ischemia and stroke.

\section{Epidemiology and clinical significance of HF} Approximately 40.0 million individuals are living with HF worldwide. ${ }^{3}$ As of 2011 in the United States, there are approximately 5.7 million patients with $\mathrm{HF}$, and approximately 870,000 patients are newly diagnosed with $\mathrm{HF}^{10}{ }^{10}$ It has been reported that $1 \%$ to $2 \%$ of the population has $\mathrm{HF}$, and the prevalence increases with age. ${ }^{11}$ The prevalence rate is $<1 \%$ in individuals under 40 years of age, but is $>10 \%$ in those over 80 years of age, and generally doubles in each decade of life. ${ }^{10}$ Therefore, the number of patients with HF is expected to increase as the population ages. In addition, decreased mortality owing to recent therapeutic improvement of cardiovascular disease may paradoxically increase the number of patients at risk of developing HF. Moreover, patients with HF have a high rate of re-hospitalization (44\% within 1 year of discharge) $)^{12}$ and mortality ( 20\% after 1 year and $\sim 50 \%$ after 5 years). ${ }^{7}$ The mortality rate of $\mathrm{HF}$ is higher than that of most cancers. ${ }^{13}$ Therefore, managing patients with $\mathrm{HF}$ is important in reducing social and economic burden as well as medical burden.

\section{Relationship between HF and neurologic diseases}

\section{Stroke}

Prevalence of stroke in patients with HF: the rate of stroke increased significantly in HF

Previous studies showed that approximately $10 \%$ to $24 \%$ of patients with stroke have $\mathrm{HF}_{1}^{14-17}$ and $\mathrm{HF}$ appears to be the cause of stroke in $9 \%$ of the patients. ${ }^{18,19}$ Patients with stroke and HF have higher mortality rates, more severe neurologic deficits, and longer hospital stays than those without HF. ${ }^{19}$ According to the Framingham study, ${ }^{5}$ the risk of ischemic stroke was two to three times higher in patients with $\mathrm{HF}$ than in those without $\mathrm{HF}$, which was also supported by other community-based studies. ${ }^{4,6}$ Recently, a population-based cohort study reported that patients with HF had a higher risk of all subtypes of stroke, as well as ischemic stroke, than the general population. ${ }^{20}$ These results suggest that there is no doubt that the risk of stroke is increased in patients with HF. However, as HF is often accompanied by traditional risk factors for stroke, such as hypertension, coronary artery disease, AF, diabetes mellitus, and obesity, ${ }_{1}^{11}$ it remains controversial that $\mathrm{HF}$ itself is an independent stroke risk factor. ${ }^{4,22-27}$ Nevertheless, a recent 30-year population-based cohort study demonstrated a significant relationship between HF and short-term and long-term risks of all stroke subtypes even after adjustment for a range of confounders, including AF or atrial flutter. ${ }^{20}$

\section{HF with AF}

Untreated AF can cause ventricular dysfunction via tachycardia-induced cardiomyopathy and promote deterioration in preexisting HF with loss of atrial contraction for ventricular filling. ${ }^{28}$ Patients with HF are also more likely to develop AF owing to changes in hemodynamics (i.e., pressure and volume overload) and cellular changes, such as fibrosis and/or automaticity, in association with shared risk factors, such as hypertension, age, diabetes, metabolic syndrome, and arteriosclerosis. ${ }^{29} \mathrm{Al}-$ though HF and AF can occur independently, the prevalence of $\mathrm{HF}$ and $\mathrm{AF}$ increases further in the presence of each other, and these two entities often co-exist in the same population. ${ }^{29,30}$ According to the Framingham Heart Study, AF occurred in more than half (57\%) of the individuals with $\mathrm{HF}$, and HF occurred in over one-thirds (37\%) of the individuals with $\mathrm{AF}^{31}$ Patients with $\mathrm{HF}$ and $\mathrm{AF}$ are more prone to develop stroke and had a 5 -fold increased risk than the control population. ${ }^{32} \mathrm{~A}$ recent meta-analysis showed that there was no difference between patients with AF with $\mathrm{HFpEF}$ and $\mathrm{HFrEF}$ in terms of 
stroke risk, although the all-cause mortality rate was significantly higher in the latter than in the former. ${ }^{33}$ Interestingly, Mogensen et al. ${ }^{34}$ reported that the type of AF (paroxysmal, persistent or permanent, or new-onset) may be associated with the stroke risk in patients with HFrEF. In this study, persistent or permanent AF did not increase the stroke risk; however, paroxysmal (hazard ratio [HR], 1.34; 95\% confidence interval [Cl], 1.02 to 1.76$)$ and new-onset ( $\mathrm{HR}, 2.20 ; 95 \% \mathrm{Cl}, 1.25$ to 3.88 ) AF significantly increased the risk when compared to the absence of AF.

\section{HF with sinus rhythm}

There were only a few studies investigating the relationship between stroke and $\mathrm{HF}$ with sinus rhythm, and the results were limited by their small sample size, short-term follow-up, and other confounding factors, such as the incidence of AF and the use of $\mathrm{HF}$ medications as well as antithrombotics. ${ }^{4-6,23}$ However, there has been a consensus that the risk of ischemic stroke, thromboembolism, and death increases in patients with HF even with sinus rhythm ${ }_{1}{ }^{35}$ which is also consistent with the findings of several recent studies. ${ }^{20,32,36,37}$

Two population-based cohort studies recently demonstrated that patients with HF had an increased risk for ischemic stroke irrespective of AF when compared with the general population. ${ }^{20,32}$ Results from a Korean cohort showed that patients with $\mathrm{HF}$ but without AF had a 3.5-fold increased risk for stroke, while those with $\mathrm{HF}$ and $\mathrm{AF}$ demonstrated a $>5$-fold increased risk for stroke. ${ }^{32}$ In particular, a multivariate analysis performed on a Danish cohort revealed that the risk of stroke in patients with $\mathrm{HF}$ was five times higher during the initial 30 days following incident $\mathrm{HF}$ hospitalization even after adjusting for matching factors, including $A F^{20}$ However, both studies did not differentiate between the HF types, HFrEF and HFpEF, and the diagnoses were based on ICD (International Classification of Diseases) codes. ${ }^{20,32}$

There were analyses of the risk for stroke according to the $\mathrm{HF}$ type and presence of AF using pooled data from existing HF randomized clinical trials (Table 1) ${ }^{36,37}$ Among patients with $\mathrm{HFrEF}$, those without AF had a lower stroke risk than those with $\mathrm{AF}$ (1.2\% per year vs. $1.6 \%$ per year, respectively). ${ }^{37} \mathrm{Al}-$ though patients with HFpEF but without AF also showed a lower stroke risk than those with AF (1.0\% per year vs. 1.8\% per year, respectively), ${ }^{36}$ the risk was still substantial and higher than that in the general population. ${ }^{32}$ However, even in the absence of $A F$, if patients with $H F$ also presented with significant comorbidities of stroke, their stroke risk was comparable to that of patients with $\mathrm{HF}$ and $\mathrm{AF}^{32,36,37}$ In addition, the overall stroke risk in patients without $\mathrm{AF}$ was similar to that in patients with $\mathrm{HFpEF}$ and $\mathrm{HFrEF}$, although the risk was higher in patients with HFrEF than in those with HFpEF in high-stroke risk subgroups (Table 1). ${ }^{36,37}$ Nevertheless, a severely impaired left ventricular ejection fraction is a well-known risk factor for stroke. $^{26,27,38}$

As will be described later, the mechanism of stroke in HF has mostly been studied in patients with HFrEF; however, data explaining this mechanism in patients with $\mathrm{HFpEF}$ remains limited. In patients with $\mathrm{HFpEF}$, alterations in the cardiac structure, e.g., left ventricular hypertrophy or concentric remodeling and diffuse myocardial fibrosis, have been reported..$^{39-41}$ Increased myocardial stiffness due to these structural changes and left atrial enlargement may lead to blood stasis, which in turn contributes to stroke. In addition to these structural changes, prothrombotic trends are observed in $\mathrm{HFpEF}$, which will also be described later.

\section{Left ventricular wall motion abnormality}

Left ventricular wall motion abnormality (LVWMA) has been suggested as a low or an uncertain risk factor in terms of cerebral embolic risk. ${ }^{42}$ LVWMA is associated with regional blood stasis and incomplete ventricular emptying, which may increase thrombogenicity and induce intraventricular thrombus formation. ${ }^{43-45}$ However, as LVWMA may be an epiphenomenon of underlying cardiac diseases, such as myocardial infarction or dilated cardiomyopathy, it is difficult to evaluate the risk of

Table 1. Annual stroke risk (\%/year) stratified by type of heart failure, presence of AF and anticoagulant use (if AF present)

\begin{tabular}{|c|c|c|c|c|c|}
\hline & \multirow{2}{*}{ Without AF (\%/yr) } & \multicolumn{3}{|c|}{ With AF (\%/yr) } & \multirow{2}{*}{ Reference } \\
\hline & & Overall & Warfarin (+) & Warfarin (-) & \\
\hline HFrEF* (high risk group) $^{+}$ & $1.2(2.0)$ & 1.6 & $1.2^{\ddagger}$ & 2.2 & 37 \\
\hline $\mathrm{HFpEF}^{\S}$ (high risk group) $^{+}$ & $1.0(1.6)$ & 1.8 & 1.5 & 2.2 & 36 \\
\hline
\end{tabular}

$\mathrm{AF}$, atrial fibrillation; $\mathrm{HFrEF}$, heart failure with reduced ejection fraction; $\mathrm{HFpEF}$, heart failure with preserved ejection fraction.

*From the Controlled Rosuvastatin in Multinational Trial Heart Failure (CORONA) and the Gruppo Italiano per lo Studio della Sopravvivenza nell'Insufficienza cardiaca-Heart Failure (GISSI-HF) trials; ${ }^{\dagger}$ According to the author's specific model for stroke based on clinical variables such as previous stroke, diabetes treated with insulin, age, body mass index and New York Heart Association functional class; ${ }^{*}$ Estimated from the analysis of reference $37 ;{ }^{\circ}$ From the Candesartan in Heart failure Assessment of Reduction in Mortality and Morbidity-Preserved (CHARM-Preserved) trial and the Irbesartan in Heart Failure with Preserved Systolic Function trial (I-Preserve) trial. 
stroke for LVWMA itself.

A population-based study reported a strong correlation between LVWMA and cardiovascular events in adults without clinically evident cardiovascular disease ${ }^{46}$ (segmental LVWMA: $\mathrm{HR}, 2.5 ; 95 \% \mathrm{Cl}, 1.9$ to $3.3 ; P<0.0001$ and global LVWMA: HR, $2.4 ; 95 \% \mathrm{Cl}, 1.4$ to $4.1 ; P=0.001)$. The statistical power was weak; however, the risk of stroke increased by 1.7-fold (95\% $\mathrm{Cl}, 0.8$ to $4.0 ; P=0.20$ ) in the presence of segmental LVWMA and by 3.1 -fold ( $95 \% \mathrm{Cl}, 1.0$ to $9.8 ; P=0.06$ ) in the presence of global LVWMA. ${ }^{46}$ In a recent observational study involving patients with stroke without high-risk cardioembolic conditions, such as myocardial infarct, dilated cardiomyopathy, and ejection fraction of $<30 \%$, the presence of LVWMA was associated with any type of stroke $(\mathrm{HR}, 1.75 ; 95 \% \mathrm{Cl}, 1.29$ to 2.36 ; $P<0.001)$ or ischemic stroke, specifically $(\mathrm{HR}, 1.70 ; 95 \% \mathrm{Cl}$, 1.22 to $2.38 ; P=0.002){ }^{47}$ Interestingly, in the subgroup analysis of this study, antithrombotic treatment, including anticoagulation, did not alter the effect of LVWMA on the recurrence of stroke. However, statin treatment reduced the effect of LVWMA on the stroke outcomes. Given the beneficial effect of statins on coronary artery disease, ${ }_{1}^{48}$ atherosclerotic stroke, ${ }^{49}$ and cardioembolic stroke, ${ }^{50}$ it is necessary to evaluate unrecognized cardiac diseases, and at least statin treatment might be considered for stroke prevention in patients with LWWMA.

\section{"Silent" stroke in HF}

The development of imaging technology has increased the prevalence of magnetic resonance imaging-detected silent stroke. ${ }^{19}$ An increased recognition of silent stroke might improve our understanding of the relationship between stroke and $\mathrm{HF}^{51}$ Several studies have reported that silent stroke also occurs more frequently in patients with $\mathrm{HF}^{52-55}$ The independent risk factors associated with silent stroke in HF are as follows: (1) impaired left ventricular function; (2) restrictive diastolic filling patterns on echocardiography; (3) left atrial and aortic spontaneous echo contrast; and (4) complex or calcified atherosclerotic lesions in the aorta. ${ }^{51,52,56}$ Such silent stroke is often described as a precursor of symptomatic strokes; however, the clinical implication of a high prevalence of silent stroke is limited..$^{51}$ However, the high prevalence of silent stroke in HF might be an indirect evidence that HF creates a stroke-prone environment and is likely to contribute to cognitive impairments, which are common in patients with $\mathrm{HF}^{19}$

In summary, patients with $\mathrm{HF}$ often have many risk factors for stroke, such as $A F$, and $H F$ itself also increases the stroke risk. For these reasons, patients with HF have a greater incidence of stroke than the general population. Furthermore, the prognosis after stroke is worse in the presence of $\mathrm{HF}$ than in the absence of HF. Given this relationship between HF and stroke, a new approach to stroke prevention in patients with $\mathrm{HF}$ is needed.

\section{Brain injury resulting from HF}

In addition to stroke, brain injury is increasingly recognized as

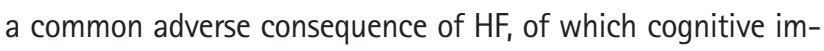
pairment is well known. ${ }^{57,58}$ Cognitive impairment in $\mathrm{HF}$ includes attention and learning deficits, reduced psychomotor speed, diminished executive function, specific subtypes of memory dysfunctions, and to a lesser degree, language impairment and reduced visuospatial performance. ${ }^{57,59,60}$ After adjustment for age, socioeconomic status, and education, worse cognitive performances were reported in $\mathrm{HF}$, which was observed not only in decompensated patients but also in stable patients..$^{57,59-61}$ Patients with HF also showed worse cognitive performances than patients with comorbidities, such as hypertension or ischemic heart disease. ${ }^{59,62}$ Although only a few studies investigated cognitive impairment according to the systolic function, one study showed that patients with HFrEF scored poorly on visuospatial/executive function, language domain, and attention domain, whereas those with HFpEF scored poorly on delayed recall and abstraction domain. ${ }^{63}$ The severity of HF was related to the increased risk of cognitive impairments, and HF treatment may improve patients' cognition. ${ }^{58,64}$

Several studies have reported structural changes, such as gray matter atrophy and white matter hyperintensities, in $\mathrm{HF}^{53,59}$ These changes were also observed in stable as well as in decompensated patients. Interestingly, in these studies, cortical gray matter loss in HF suggests that mechanisms other than hypoperfusion are involved in brain injury, as the vasculature is rich in the cortical gray matter. ${ }^{57,59}$

It is thought that various factors cause brain injury in HF. One of the most well-known mechanisms for brain injury in HF is diminished cerebral blood flow. ${ }^{57}$ In addition, changes in neurohormones, such as cortisol and catecholamine; inflammatory responses associated with myocardial injury; and nutritional deficiency, such as thiamine deficiency, are known to cause brain injury in $\mathrm{HF}^{57}$

\section{Mechanism of stroke in HF}

Traditionally, the following are the known causes of ischemic stroke: (1) embolism to the brain of cardiac or aortic origin (i.e., myocardial infarction, AF, valvular heart disease, complicated aortic plaque, or patent foramen ovale); (2) cerebral ischemia due to perfusion failure and artery-to-artery embolism (i.e., large artery atherosclerotic plaque, small vessel disease or oc- 
clusion, or vasculitis); and (3) thrombosis (prothrombotic state). ${ }^{65}$ Not surprisingly, HF comprises all of these. Therefore, to elucidate the mechanism of stroke in $\mathrm{HF}$, either thromboembolism or hypoperfusion should be explained.

\section{Thromboembolism}

Stroke in $\mathrm{HF}$ is thought to be caused mostly by a thromboembolic etiology. ${ }^{66}$ Approximately 150 years ago, three conditions (Virchow's triad: abnormalities of the blood flow, vessel wall, and blood constituents) were mentioned as prerequisites for thrombogenesis. Not surprisingly, patients with $\mathrm{HF}$, particularly HFrEF, have all three conditions. ${ }^{67}$

First, akinetic ventricular segments and dilated left atrium or ventricle with stasis of the blood flow seen in HF may increase thrombus formation via a mechanism similar to that of $\mathrm{AF}$ (blood flow abnormalities). ${ }^{68-72}$ To demonstrate that HF itself can cause stroke, it is necessary to explain that such thromboembolisms can occur in HF without AF or systolic dysfunction. Therefore, much research has been conducted on the remaining prerequisites, such as abnormalities of the vessel walls and blood constituents in addition to the first prerequisite of the Virchow's triad, "stasis."

Second, patients with HF are in the prothrombotic state (abnormal blood constituents). ${ }^{73-84}$ The prothrombotic state of HF was supported by the observation of platelet hyperactivity, increased thrombin generation, and impaired fibrinolysis. ${ }^{74,82,85}$ This prothrombotic state was further enhanced by the activated sympathetic nervous system and renin-angiotensin-aldosterone system and by systemic inflammation, which are the characteristics of HF. ${ }^{74,82,86}$ These prothrombotic trends were also found in $\mathrm{HFpEF}_{i}{ }^{73}$ thus, the thrombotic profile in $\mathrm{HF}$ was observed regardless of systolic dysfunction.

Third, there are functional and/or structural damages in the blood vessels due to endothelial dysfunction or atherosclerosis in HF (vessel wall abnormalities). ${ }^{81,82,87}$ In a defective endothelium, the release of endothelium-derived nitric oxide in response to stimuli is impaired, which, in turn, may promote monocyte and platelet adhesion to the endothelium, leading to thrombosis and thromboembolism. ${ }^{67}$ In addition, the level of von Willebrand factor, a marker that reflects endothelial damage or dysfunction, is abnormally high in $\mathrm{HF}$, which appears to be involved in making a hypercoagulable state in $\mathrm{HF}^{81,82,85}$

\section{Hypoperfusion}

Contemporary data have shown that the cerebral blood flow can be abnormal in $\mathrm{HF}^{57}$ The "hypoperfused" state in HF is explained by a low cardiac output as well as a compromised autoregulation..$^{88,89}$ In HF, carbon dioxide levels fluctuate, and cerebrovascular reactivity, a response of cerebral vasculature to high carbon dioxide levels, is also abnormal. ${ }^{88,90,91}$ In this hypoperfused condition, specific areas of the brain that are supplied by the deep penetrating arteries, lack collateral flow, or are located at the junction supplied by the anterior, middle, or posterior cerebral artery are vulnerable to ischemic damage.

Based on the increased arterial stiffness and reduced vasodilatory reserve in $\mathrm{HFpEF}^{92}$ it may be assumed that the cerebral blood flow has also decreased in HFpEF. However, no study has investigated how the cerebral blood flow changes in HFpEF.

\section{Atherosclerosis}

In a cohort study of acute stroke, ${ }^{93}$ the mechanism of stroke in patients with HF but without AF was associated with the etiology of HF. According to this study, valvular heart disease and dilated cardiomyopathy were mainly associated with cardioembolic stroke, whereas HF due to coronary artery disease or hypertension was mainly associated with atherosclerotic and lacunar strokes, respectively. Considering that coronary heart disease is the main cause of $\mathrm{HF}_{1}^{94-97}$ followed by hypertension and diabetes, atherosclerosis is also thought to contribute to stroke development in patients with HF.

\section{Stroke prevention in patients with HF}

\section{Current guidelines and previous studies}

\section{HF with AF}

The use of non-vitamin $\mathrm{K}$ antagonist oral anticoagulant (NOAC) as well as warfarin in patients with AF has been extensively studied. The current guidelines recommend assessing stroke risks in patients with $\mathrm{AF}$ using the $\mathrm{CHA}_{2} \mathrm{DS}_{2}$-VASc scoring system. ${ }^{98,99}$ In both the American College of Cardiology/American Heart Association and European Society of Cardiology guidelines, oral anticoagulation is strongly recommended for patients with a $\mathrm{CHA}_{2} \mathrm{DS}_{2}$-VASc score of 2 or more. ${ }^{98,99}$ In the case of a $\mathrm{CHA}_{2} \mathrm{DS}_{2}$-VASc score of 1 , the American guideline permits all three options (no antithrombotic treatment, oral anticoagulant, or aspirin). ${ }^{99}$ However, the more recently published European guideline recommends the use of oral anticoagulation as class Ila with level of evidence $B$, as there is a growing evidence in which oral anticoagulants may be beneficial in men with a $\mathrm{CHA}_{2} \mathrm{DS}_{2}$-VASc score of 1 and in women with a $\mathrm{CHA}_{2} \mathrm{DS}_{2}$-VASc score of $2 .^{98}$ As the $\mathrm{CHA}_{2} \mathrm{DS}_{2}$-VASc score is at least 1 in patients with $\mathrm{HF}$, an anticoagulation in those with $\mathrm{HF}$ and $\mathrm{AF}$ should be considered. In patients with contraindications to anticoagulants, such as high bleeding risks, left atrial appendage occlusion may be considered as class Ilb with level of evidence $B{ }^{98}$ 


\section{HF without $A F$}

There have been four trials (Warfarin versus Aspirin in Reduced Cardiac Ejection Fraction [WARCEF], Warfarin and Antiplatelet Therapy in Chronic Heart Failure [WATCH], Heart Failure Longterm Antithrombotic Study [HELAS], and Warfarin/Aspirin Study in Heart Failure [WASH]) of stroke prevention in patients with HFrEF who maintained sinus rhythm. In the WASH and HELAS trials, there was no significant difference between patients receiving warfarin, aspirin, and placebo at the composite endpoint of death, stroke, or myocardial infarction. ${ }^{100,101}$ However, these trials included a small cohort. The WATCH trial, which had a larger cohort than the WASH trial, showed that the incidence of ischemic stroke was further reduced with warfarin compared to aspirin or clopidogrel. However, the primary composite outcome of all-cause mortality, nonfatal myocardial infarction, and nonfatal stroke was neutral among the three antithrombotic groups. ${ }^{102}$ In the WARCEF trial, which was the most recent and largest study among the four trials, the incidence of ischemic stroke was lower with warfarin than with aspirin (0.72 events per 100 patient-years vs. 1.36 per 100 patient-years; $\mathrm{HR}, 0.52 ; 95 \% \mathrm{Cl}, 0.33$ to 0.82 ); however, the benefit was counteracted by an increase in major bleeding events (1.78 events per 100 patient-years vs. 0.87 per 100 patient-years; $\mathrm{HR}, 2.05 ; 95 \% \mathrm{Cl}, 1.36$ to 3.12 ). ${ }^{103} \mathrm{~A}$ meta-analysis of these four trials showed that stroke prevention using warfarin was evident in these patients. ${ }^{104}$ In this analysis, oral anticoagulation using warfarin reduced the stroke risk by $41 \%$ compared with that using aspirin. However, the risk of bleeding doubled, which offset the benefits of stroke prevention. Furthermore, there was no difference in the mortality rate, incidence rate of myocardial infarction, and hospitalization rate between the groups.

Although no study has investigated anticoagulation for stroke prevention, specifically in patients with HFpEF but without $A F$, a real-world cohort study with incident HF cases excluding AF showed a significant reduction in the composite of death or all strokes with warfarin use. ${ }^{22}$ However, the result was limited by the absence of data to confirm the proportions with HFpEF or HFrEF. Further studies targeting patients with $\mathrm{HFpEF}$ but without AF for stroke prevention are needed.

Based on the results of previous studies, the use of warfarin for the prevention of stroke in patients with sinus rhythm seems to be beneficial at least in HFrEF. However, the routine use of warfarin in patients with HFrEF but without AF appears to be limited, as benefits are offset by the risk of bleeding. This suggests two possibilities. First, anticoagulation may be beneficial only for certain patients with a higher stroke risk beyond bleeding risk. Therefore, the adequate stratification of patients with a high stroke risk may be important. Second, the use of oral anticoagulants can be justified if the anticoagulants have a broad spectrum of safety profile with a lower bleeding risk. Because of this, NOACs are expected to be a treatment option for stroke prevention in HF in the future.

\section{Risk stratification}

There is a continuing need for a simple clinical model to predict the stroke risk in patients with HF. Several attempts have been made to predict patients with a high stroke risk. However, no satisfactory model has yet been developed.

\section{Predictors of stroke in patients without AF}

In a previous study analyzing the risk of stroke in patients with $\mathrm{HF}$ but without $\mathrm{AF}_{1}^{37}$ several variables were reported to be associated with stroke. The authors identified five independent predictors of stroke in patients with $\mathrm{HFrEF}$ but without AF (ranked by the $\chi^{2}$ value): (1) age ( $\mathrm{HR}, 1.34 ; 95 \% \mathrm{Cl}, 1.18$ to 1.63 per 10 years); (2) New York Heart Association (NYHA) class (HR, 1.60; 95\% Cl, 1.21 to 2.12 class III/IV vs. II); (3) diabetes mellitus treated with insulin $(\mathrm{HR}, 1.87 ; 95 \% \mathrm{Cl}, 1.22$ to 2.88); (4) body mass index ( $\mathrm{HR}, 0.74 ; 95 \% \mathrm{Cl}, 0.60$ to 0.91 per $5 \mathrm{~kg} / \mathrm{m}^{2}$ up to 30$) ;$ and (5) previous stroke $(\mathrm{HR}, 1.81 ; 95 \% \mathrm{Cl}$, 1.19 to 2.74$)$. With a risk score formulated from these predictors using the coefficients for each variable, patients in the top third of this score had a rate of stroke that approximated the risk in patients with AF (Table 1). The overall c-index for this "stroke risk score" model was 0.75 ( $95 \% \mathrm{Cl}, 0.62$ to 0.86$)$. These results were consistent with those for patients with HFpEF but without $\mathrm{AF}^{36}$ This scoring system should be tested prospectively in a randomized trial.

\section{$\mathrm{CHADS}_{2}$ score}

The $\mathrm{CHADS}_{2}$ score and $\mathrm{CHA}_{2} \mathrm{DS}_{2}$-VASc score are known to be useful methods for stratifying stroke risks in patients with AF. Kondo et al. ${ }^{105}$ compared the aforementioned "stroke risk score ${ }^{\text {"37 }}$ with the $\mathrm{CHADS}_{2}$ and $\mathrm{CHA}_{2} \mathrm{DS}_{2}$-VASc scores to predict stroke in patients with HFrEF but without AF. In this study, the $\mathrm{CHADS}_{2}$ and $\mathrm{CHA}_{2} \mathrm{DS}_{2}$-VASc scores (c-index, 0.794; 95\% Cl, 0.663 to 0.925 vs. c-index, $0.740 ; 95 \% \mathrm{Cl}, 0.605$ to 0.875 , respectively), but not the "stroke risk score" (c-index, $0.625 ; 95 \%$ $\mathrm{Cl}, 0.488$ to 0.762 ), were still significantly associated with ischemic stroke. ${ }^{105}$ In terms of the discriminatory ability for ischemic stroke, the $\mathrm{CHADS}_{2}$ score had the highest area under the curve $(0.805 ; 95 \% \mathrm{Cl}, 0.719$ to 0.892$)$. In this study, the cohort size of patients with severe symptoms (NYHA III or IV) or diabetes mellitus treated with insulin was smaller than that in the previous study using the "stroke risk score." Thus, it is diffi- 
cult to evaluate it accurately. However, the possibility of the CHADS 2 score or $\mathrm{CHA}_{2} \mathrm{DS}_{2}$-VASc score as a stroke risk model in patients with HFrEF but without AF was suggested.

\section{$\mathrm{CHA}_{2} \mathrm{DS}_{2}$-VASc score}

It has been suggested in some studies that $\mathrm{CHA}_{2} \mathrm{DS}_{2}$-VASc score, which was applied to patients with $A F$, may be useful for stratifying the stroke risk when applied to patients with HF but without $A F_{1}^{32,106}$ or even to the general population. ${ }^{32}$

In a Danish cohort study, ${ }^{106} \mathrm{CHA}_{2} \mathrm{DS}_{2}$-VASc score was first used to predict ischemic stroke in patients with incident HF. In particular, the risk of ischemic stroke increased with a clear dose-response relationship as the score increased at high $\mathrm{CHA}_{2} \mathrm{DS}_{2}$-VASc scores ( $\left.\geq 4\right)$, regardless of AF. The discriminatory ability of $\mathrm{CHA}_{2} \mathrm{DS}_{2}$-VASc score was moderate, although it varied depending on the presence of AF and duration of follow-up (c-index, 0.64 to 0.71 ). Because of its modest predictive accuracy, the use of $\mathrm{CHA}_{2} \mathrm{DS} \mathrm{S}_{2}-\mathrm{VASc}$ score for stroke risk stratification may be limited in clinical practice. However, it was suggested that $\mathrm{CHA}_{2} \mathrm{DS}_{2}$-VASc score could be a useful tool for identifying "low-stroke risk" patients because $\mathrm{CHA}_{2} \mathrm{DS}_{2}-\mathrm{VASC}$ score yielded a high negative predictive value $(92 \% ; 95 \% \mathrm{Cl}$, 91 to 93) for ischemic stroke at the 1-year follow-up. Identification of patients at a "truly low" risk would be important especially because they are less likely to benefit from anticoagulation.

Recently, the use of $\mathrm{CHA}_{2} \mathrm{DS}_{2}$-VASc score was more extended. In a Korean cohort study, as the score increased, the incidence of stroke also increased across all groups studied: general control population; HF without AF group; AF without HF group; and HF with AF group. ${ }^{32}$ Although the HF without AF group had a slightly lower overall stroke rate than the AF without $\mathrm{HF}$ group, the stroke risk was comparable in both groups when the patients were stratified by $\mathrm{CHA}_{2} \mathrm{DS}_{2}$-VASc scores. ${ }^{32}$ These results suggest that we may stratify patients with $\mathrm{HF}$ at a high risk of stroke who are more likely to benefit from anticoagulation.

Although the abovementioned studies support the usefulness of $\mathrm{CHA}_{2} \mathrm{DS}_{2}-\mathrm{VASc}$ score in patients with $\mathrm{HF}$, those studies were unable to distinguish between $\mathrm{HFpEF}$ and $\mathrm{HFrEF}$.

In the $\mathrm{CHADS}_{2}$ or $\mathrm{CHA}_{2} \mathrm{DS}_{2}$-VASc scoring system, not all individual components were established as risk factors of ischemic stroke in the HF population. Previous studies on patients with HF have reported that some of these components may not be related to (e.g., age of $>75$ years, female sex, hypertension, diabetes, and vascular disease) ${ }^{6,22}$ or may even reduce (e.g., female $\mathrm{sex})^{107}$ the stroke risk. Therefore, studies on the stroke risk of each component are also necessary. In addition, the abovementioned "stroke risk score" and $\mathrm{CHADS}_{2}$ score or $\mathrm{CHA}_{2} \mathrm{DS}_{2}$ -
VASc score commonly includes age, diabetes, and prior stroke. Therefore, the stroke risk is expected to increase at least in patients with HF with these components.

\section{Time variable}

Many reports have described the risk of stroke to be much higher in the initial period following incident $\mathrm{HF}^{6,20,22,23} \mathrm{Com}$ pared with the data of the general population, data from a recent Danish nationwide registry indicated a 5-fold elevated 30-day ischemic stroke risk after first-time hospitalization for $\mathrm{HF}^{20}{ }^{20}$ It remained elevated for over 30 years (2-fold increase between 31 and 365 days and 1.5-fold increase between 1 and 30 years). In another community-based study, HF was associated with a 17-fold increased risk for ischemic stroke compared with that in the general population in the first 30 days after HF diagnosis. ${ }^{6}$ Furthermore, the risk persisted for over 5 years. The Danish Diet, Cancer and Health Cohort study showed again that the risk of ischemic stroke is time dependent. ${ }^{22}$ While it was lower than the 30-day risk, the higher risk was not normalized 6 months after the diagnosis of incident HF. Similarly, in a Dutch cohort study, the risk of ischemic stroke increased by 4.6 -fold in the first 30 days after HF diagnosis. ${ }^{23}$ Although it remains uncertain whether the ischemic stroke risk returns to the baseline values over time owing to inconsistent findings in previous studies, ${ }^{6,20,22,23}$ these studies have consistently demonstrated an increased risk of ischemic stroke in the first 30 days after the HF diagnosis. These results suggest that there might be a more efficient period for stroke prevention, albeit this hypothesis needs to be confirmed.

Taken together, anticoagulation for stroke prevention might be considered for patients with HF at a high risk based on several variables (e.g., age, diabetes, and prior stroke), especially within the first month after the diagnosis of HF. Further studies are needed to develop a clinical model to predict the stroke risk in patients with $\mathrm{HF}$, including variables, such as time interval following the diagnosis of incident HF.

\section{In the era of NOACs}

NOACs, including dabigatran, rivaroxaban, apixaban, and edoxaban, have been approved by the Food and Drug Administration based on their respective clinical trials. ${ }^{108-112}$ Sub-group analyses of these studies showed that NOACs were effective and safe in patients with HF and AF similar to warfarin (Table 2). ${ }^{113-117}$ Although there was no significant benefit in individual trials, a recent meta-analysis showed that NOACs could be better than warfarin with regard to their efficacy and safety. ${ }^{118}$ This meta-analysis showed that single-/high-dose NOACs in patients with $\mathrm{AF}$ and $\mathrm{HF}$ decreased the number of stroke/sys- 


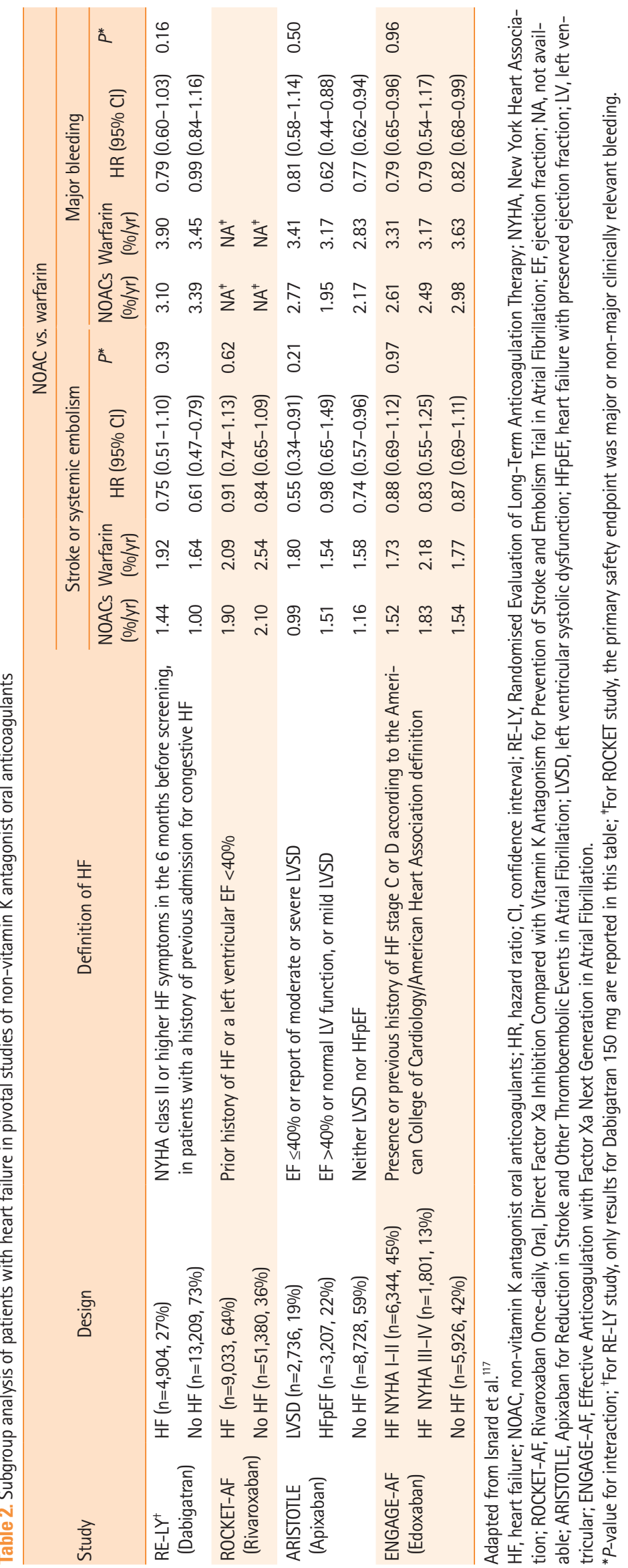

temic embolic events by $14 \%(\mathrm{OR}, 0.86 ; 95 \% \mathrm{Cl}, 0.76$ to 0.98$)$ and major bleeding events by $24 \%(O R, 0.76$; $95 \% \mathrm{Cl}, 0.67$ to 0.86 ), as compared with warfarin. ${ }^{118}$ Although clinical trials of conventional antithrombotic therapies for patients with HF but without AF failed to show a clinical benefit, NOACs might yield some differences.

In general, compared with warfarin, NOACs have rapid onset and offset of action, yield more predictable anticoagulant responses, and can be administered at fixed doses without routine monitoring, thereby simplifying therapy. ${ }^{119} \mathrm{In}$ addition, dietary vitamin $\mathrm{K}$ intake does not affect NOACs; therefore, dietary restrictions are not required. ${ }^{119}$ There are also few clinically important drug-to-drug interactions with NOACs. This profile of NOACs can be an advantage for patients with HF who often take polypharmacy ${ }^{97}$ and have a high bleeding risk due to comorbidity. Conversely, NOACs are more dependent on the kidney for excretion than warfarin. ${ }^{119}$ Therefore, in patients with renal impairments, NOACs can potentially increase their bleeding risk, and their use is limited.

Because NOACs have been shown to be safe and effective for stroke prevention in patients with $\mathrm{AF}$ and $\mathrm{HF}$, their safety and efficacy might be maintained in patients with HF but without AF. The Anti-Xa Therapy to Lower Cardiovascular Events in Addition to Standard Therapy in Subjects with Acute Coronary Syndrome-Thrombolysis In Myocardial Infarction-51 (ATLAS ACS 2-TIMI 51) trial raised the possibility of the clinical benefit of anticoagulation using NOACs in patients with HF. ${ }^{120}$ The ATLAS ACS 2-TIMI 51 trial was originally attempted to evaluate the effect of low-dose rivaroxaban in patients with acute coronary syndrome (ACS). In an unpublished subgroup analysis (Janssen Research \& Development LLC, Raritan, $\mathrm{NJ}$, USA), ${ }^{121}$ rivaroxaban $2.5 \mathrm{mg}$ twice daily reduced the incidence rates of cardiovascular death, myocardial infarction, and stroke (18.6\% placebo vs. $11.6 \%$ rivaroxaban, $P<0.001)$ as well as the all-cause mortality rate (11.1\% placebo vs. $5.3 \%$ rivaroxaban, $P<0.001)$ in patients with $\mathrm{HF}$ at the time of ACS. These results from the ATLAS ACS 2-TIMI 51 trial led to a randomized clinical trial using NOACs in patients with HF and sinus rhythm. The Coronary Artery Disease Following an Episode of Decompensated Heart Failure (COMMANDER HF) trial is currently investigating the efficacy and safety of rivaroxaban (2.5 $\mathrm{mg}$ twice daily) in reducing the risk of stroke, myocardial infarction, or even death compared with placebo in pa- 
tients with $\mathrm{HFrEF}$, without $A F$, but with a significant coronary artery disease. ${ }^{121}$

\section{Conclusions}

Stroke and HF are frequently occurring adverse events that are associated with high mortality and morbidity rates. Although $A F$, which develops in more than half of patients with $H F$, is a major risk factor for stroke, the role of $\mathrm{HF}$ itself as a risk factor for stroke has been underestimated. There is a growing evidence that $\mathrm{HF}$ itself increases the risk of stroke regardless of AF through various mechanisms, mainly by thromboembolism. However, previous studies have failed to show the benefit of warfarin in patients with HF but without $A F$, as the benefit of stroke prevention was counteracted by the increased incidence of major bleeding. Recently, studies have been conducted to identify patients with $\mathrm{HF}$ at a high stroke risk who may benefit more from anticoagulation. Based on the stroke risk prediction model, it may be plausible to select the best strategy to prevent stroke in patients with HF. Moreover, NOACs, which provide a favorable risk-benefit profile compared with warfarin, are an attractive therapeutic option.

Thus, the use of NOACs can be an effective stroke prevention strategy in patients with $\mathrm{HF}$, especially in those at a high stroke risk as well as in those in the period of a high stroke risk. This outlook needs to be proven in further studies.

\section{Disclosure}

The authors have no financial conflicts of interest.

\section{Acknowledgments}

This research was supported by a grant of the Korea Health Industry Development Institute (KHIDI), funded by the Ministry of Health \& Welfare, Republic of Korea (grant number: HI16C0483).

\section{References}

1. Feigin VL, Norrving $B$, Mensah GA. Global burden of stroke. Circ Res 2017;120:439-448.

2. Feigin VL, Krishnamurthi RV, Parmar $P$, Norrving $B$, Mensah $G A$, Bennett $D A$, et al. Update on the global burden of ischemic and hemorrhagic stroke in 1990-2013: the GBD 2013 study. Neuroepidemiology 2015;45:161-176.

3. GBD 2015 Disease and Injury Incidence and Prevalence Collaborators. Global, regional, and national incidence, prevalence, and years lived with disability for 310 diseases and in- juries, 1990-2015: a systematic analysis for the Global Burden of Disease Study 2015. Lancet 2016;388:1545-1602.

4. Pullicino PM, McClure LA, Wadley VG, Ahmed A, Howard VJ, Howard $G$, et al. Blood pressure and stroke in heart failure in the REasons for Geographic And Racial Differences in Stroke (REGARDS) study. Stroke 2009;40:3706-3710.

5. Kannel WB, Wolf PA, Verter J. Manifestations of coronary disease predisposing to stroke. The Framingham study. JAMA 1983;250:2942-2946.

6. Witt BJ, Brown RD Jr, Jacobsen SJ, Weston SA, Ballman KV, Meverden RA, et al. Ischemic stroke after heart failure: a community-based study. Am Heart J 2006;152:102-109.

7. Ziaeian B, Fonarow GC. Epidemiology and aetiology of heart failure. Nat Rev Cardiol 2016;13:368-378.

8. Ponikowski P, Voors AA, Anker SD, Bueno H, Cleland JG, Coats AJ, et al. 2016 ESC guidelines for the diagnosis and treatment of acute and chronic heart failure: the task force for the diagnosis and treatment of acute and chronic heart failure of the European Society of Cardiology (ESC) Developed with the special contribution of the Heart Failure Association (HFA) of the ESC. Eur Heart J 2016;37:2129-2200.

9. Writing Group Members, Lloyd-Jones D, Adams RJ, Brown TM, Carnethon M, Dai $S$, et al. Heart disease and stroke statistics: 2010 update. A report from the American Heart Association. Circulation 2010;121:e46-e215.

10. Writing Group Members, Mozaffarian D, Benjamin EJ, Go AS, Arnett DK, Blaha MJ, et al. Heart disease and stroke statistics: 2016 update. A report from the American Heart Association. Circulation 2016;133:e38-e360.

11. Ponikowski $\mathrm{P}$, Anker SD, AlHabib KF, Cowie MR, Force TL, Hu $S$, et al. Heart failure: preventing disease and death worldwide. ESC Heart Fail 2014;1:4-25.

12. Maggioni AP, Dahlström U, Filippatos $G$, Chioncel $O$, Crespo Leiro $M$, Drozdz J, et al. EURObservational Research Programme: regional differences and 1-year follow-up results of the Heart Failure Pilot Survey (ESC-HF Pilot). Eur J Heart Fail 2013;15:808-817.

13. Mamas MA, Sperrin M, Watson MC, Coutts A, Wilde K, Burton $C$, et al. Do patients have worse outcomes in heart failure than in cancer? A primary care-based cohort study with 10-year follow-up in Scotland. Eur J Heart Fail 2017;19:1095-1104.

14. Divani AA, Vazquez G, Asadollahi M, Qureshi Al, Pullicino P. Nationwide frequency and association of heart failure on stroke outcomes in the United States. J Card Fail 2009;15:11-16.

15. Ois $A$, Gomis $M$, Cuadrado-Godia E, Jiménez-Conde J, Rodríguez-Campello $A$, Bruguera J, et al. Heart failure in acute ischemic stroke. J Neurol 2008;255:385-389.

16. Hays $A G$, Sacco RL, Rundek $T$, Sciacca RR, Jin $Z$, Liu $R$, et al. 
Left ventricular systolic dysfunction and the risk of ischemic stroke in a multiethnic population. Stroke 2006;37:1715-1719.

17. Appelros P, Nydevik I, Viitanen M. Poor outcome after firstever stroke: predictors for death, dependency, and recurrent stroke within the first year. Stroke 2003;34:122-126.

18. Pullicino $\mathrm{P}$, Homma S. Stroke in heart failure: atrial fibrillation revisited? J Stroke Cerebrovasc Dis 2010;19:1-2.

19. Haeusler KG, Laufs U, Endres M. Chronic heart failure and ischemic stroke. Stroke 2011;42:2977-2982.

20. Adelborg K, Szépligeti S, Sundbøll J, Horváth-Puhó E, Henderson VW, Ording $A$, et al. Risk of stroke in patients with heart failure: a population-based 30-year cohort study. Stroke 2017:48:1161-1168.

21. Sacco RL, Benjamin EJ, Broderick JP, Dyken M, Easton JD, Feinberg WM, et al. American Heart Association Prevention Conference. IV. Prevention and rehabilitation of stroke. Risk factors. Stroke 1997;28:1507-1517.

22. Lip GY, Rasmussen LH, Skjøth F, Overvad K, Larsen TB. Stroke and mortality in patients with incident heart failure: the Diet, Cancer and Health (DCH) cohort study. BMJ Open 2012;2:e000975.

23. Alberts VP, Bos MJ, Koudstaal P, Hofman A, Witteman JC, Stricker $B$, et al. Heart failure and the risk of stroke: the Rotterdam Study. Eur J Epidemiol 2010;25:807-812.

24. Freudenberger RS, Hellkamp AS, Halperin JL, Poole J, Anderson J, Johnson $G$, et al. Risk of thromboembolism in heart failure: an analysis from the Sudden Cardiac Death in Heart Failure Trial (SCD-HeFT). Circulation 2007;115:2637-2641.

25. Szummer KE, Solomon SD, Velazquez EJ, Kilaru R, McMurray

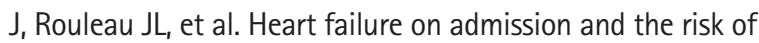
stroke following acute myocardial infarction: the VALIANT registry. Eur Heart J 2005;26:2114-2119.

26. Loh E, Sutton MS, Wun CC, Rouleau JL, Flaker GC, Gottlieb SS, et al. Ventricular dysfunction and the risk of stroke after myocardial infarction. N Engl J Med 1997;336:251-257.

27. Dries DL, Rosenberg YD, Waclawiw MA, Domanski MJ. Ejection fraction and risk of thromboembolic events in patients with systolic dysfunction and sinus rhythm: evidence for gender differences in the studies of left ventricular dysfunction trials. J Am Coll Cardiol 1997;29:1074-1080.

28. Anter $E_{1}$ Jessup $M$, Callans DJ. Atrial fibrillation and heart failure: treatment considerations for a dual epidemic. Circulation 2009;119:2516-2525.

29. Hohendanner F, Heinzel FR, Blaschke F, Pieske BM, Haverkamp W, Boldt HL, et al. Pathophysiological and therapeutic implications in patients with atrial fibrillation and heart failure. Heart Fail Rev 2018;23:27-36.

30. Abraham JM, Connolly SJ. Atrial fibrillation in heart failure: stroke risk stratification and anticoagulation. Heart Fail Rev
2014;19:305-313.

31. Santhanakrishnan R, Wang N, Larson MG, Magnani JW, McManus DD, Lubitz SA, et al. Atrial fibrillation begets heart failure and vice versa: temporal associations and differences in preserved versus reduced ejection fraction. Circulation 2016;133:484-492.

32. Kang SH, Kim J, Park JJ, Oh IY, Yoon CH, Kim HJ, et al. Risk of stroke in congestive heart failure with and without atrial fibrillation. Int J Cardiol 2017;248:182-187.

33. Kotecha D, Chudasama R, Lane DA, Kirchhof P, Lip GY. Atrial fibrillation and heart failure due to reduced versus preserved ejection fraction: a systematic review and meta-analysis of death and adverse outcomes. Int J Cardiol 2016;203:660-666.

34. Mogensen UM, Jhund PS, Abraham WT, Desai AS, Dickstein $\mathrm{K}$, Packer $\mathrm{M}$, et al. Type of atrial fibrillation and outcomes in patients with heart failure and reduced ejection fraction. J Am Coll Cardiol 2017;70:2490-2500.

35. Lip GY, Piotrponikowski P, Andreotti F, Anker SD, Filippatos G, Homma S, et al. Thromboembolism and antithrombotic therapy for heart failure in sinus rhythm: an executive summary of a joint consensus document from the ESC Heart Failure Association and the ESC Working Group on Thrombosis. Thromb Haemost 2012;108:1009-1022.

36. Abdul-Rahim AH, Perez AC, Maclsaac RL, Jhund PS, Claggett $B L$, Carson $P E$, et al. Risk of stroke in chronic heart failure patients with preserved ejection fraction, but without atrial fibrillation: analysis of the CHARM-Preserved and I-Preserve trials. Eur Heart J 2017;38:742-750.

37. Abdul-Rahim AH, Perez AC, Fulton RL, Jhund PS, Latini R, Tognoni $\mathrm{G}$, et al. Risk of stroke in chronic heart failure patients without atrial fibrillation: analysis of the Controlled Rosuvastatin in Multinational Trial Heart Failure (CORONA) and the Gruppo Italiano per lo Studio della Sopravvivenza nell'Insufficienza Cardiaca-Heart Failure (GISSI-HF) trials. Circulation 2015;131:1486-1494.

38. Freudenberger RS, Hellkamp AS, Halperin JL, Poole J, Anderson J, Johnson G, et al. Risk of thromboembolism in heart failure. Circulation 2007;115:2637-2641.

39. Su MY, Lin LY, Tseng YH, Chang CC, Wu CK, Lin JL, et al. CMR-verified diffuse myocardial fibrosis is associated with diastolic dysfunction in HFpEF. JACC Cardiovasc Imaging 2014;7:991-997.

40. Zile MR, Gottdiener JS, Hetzel SJ, McMurray JJ, Komajda M, McKelvie $R$, et al. Prevalence and significance of alterations in cardiac structure and function in patients with heart failure and a preserved ejection fraction. Circulation 2011;124:2491-2501.

41. Borlaug BA, Paulus WJ. Heart failure with preserved ejection fraction: pathophysiology, diagnosis, and treatment. Eur Heart 
J 2011;32:670-679.

42. Ferro JM. Cardioembolic stroke: an update. Lancet Neurol 2003;2:177-188.

43. Cusick DA, Bonow RO, Chaudhry FA. Left ventricular apical thrombus and myocardial viability: a dobutamine stress echocardiographic study. Echocardiography 2000;17(6 Pt 1):547-554.

44. Merlini PA, Bauer KA, Oltrona L, Ardissino D, Cattaneo M, Belli C, et al. Persistent activation of coagulation mechanism in unstable angina and myocardial infarction. Circulation 1994; 90:61-68.

45. Bhatnagar SK, Hudak A, Al-Yusuf AR. Left ventricular thrombosis, wall motion abnormalities, and blood viscosity changes after first transmural anterior myocardial infarction. Chest 1985;88:40-44.

46. Cicala S, de Simone G, Roman MJ, Best LG, Lee Et, Wang W, et al. Prevalence and prognostic significance of wall-motion abnormalities in adults without clinically recognized cardiovascular disease: the Strong Heart Study. Circulation 2007;116:143150.

47. Choi JY, Cha J, Jung JM, Seo WK, Oh K, Cho KH, et al. Left ventricular wall motion abnormalities are associated with stroke recurrence. Neurology 2017;88:586-594.

48. Shepherd J, Cobbe SM, Ford I, Isles CG, Lorimer AR, MacFarlane $\mathrm{PW}$, et al. Prevention of coronary heart disease with pravastatin in men with hypercholesterolemia. West of Scotland Coronary Prevention Study Group. NEngl J Med 1995;333:1301-1307.

49. Hong KS, Lee JS. Statins in acute ischemic stroke: a systematic review. J Stroke 2015;17:282-301.

50. Choi JY, Seo WK, Kang SH, Jung JM, Cho KH, Yu S, et al. Statins improve survival in patients with cardioembolic stroke. Stroke 2014;45:1849-1852.

51. Hassell $M E$, Nijveldt $R$, Roos $Y B$, Majoie $C B$, Hamon $M$, Piek $J \mathrm{~J}$, et al. Silent cerebral infarcts associated with cardiac disease and procedures. Nat Rev Cardiol 2013;10:696-706.

52. Kozdag G, Ciftci E, Ural D, Sahin T, Selekler M, Agacdiken A, et al. Silent cerebral infarction in chronic heart failure: ischemic and nonischemic dilated cardiomyopathy. Vasc Health Risk Manag 2008;4:463-469.

53. Vogels RL, van der Flier WM, van Harten B, Gouw AA, Scheltens $P_{1}$ Schroeder-Tanka JM, et al. Brain magnetic resonance imaging abnormalities in patients with heart failure. Eur $J$ Heart Fail 2007;9:1003-1009.

54. Siachos T, Vanbakel A, Feldman DS, Uber W, Simpson KN, Pereira NL. Silent strokes in patients with heart failure. J Card Fail 2005;11:485-489.

55. Schmidt $R$, Fazekas F, Offenbacher $H$, Dusleag J, Lechner $H$. Brain magnetic resonance imaging and neuropsychologic evaluation of patients with idiopathic dilated cardiomyopathy. Stroke 1991;22:195-199.
56. Kozdag G, Ciftci E, Vural A, Selekler M, Sahin T, Ural D, et al. Silent cerebral infarction in patients with dilated cardiomyopathy: echocardiographic correlates. Int J Cardiol 2006;107:376-381.

57. Havakuk O, King KS, Grazette L, Yoon AJ, Fong M, Bregman $\mathrm{N}$, et al. Heart failure-induced brain injury. J Am Coll Cardiol 2017;69:1609-1616.

58. Dardiotis E, Giamouzis G, Mastrogiannis D, Vogiatzi C, Skoularigis J, Triposkiadis F, et al. Cognitive impairment in heart failure. Cardiol Res Pract 2012;2012:595821.

59. Almeida OP, Garrido GJ, Beer C, Lautenschlager NT, Arnolda L, Flicker $\mathrm{L}$ Cognitive and brain changes associated with ischaemic heart disease and heart failure. Eur Heart J 2012;33:1769-1776.

60. Vogels RL, Scheltens P, Schroeder-Tanka JM, Weinstein HC. Cognitive impairment in heart failure: a systematic review of the literature. EurJ Heart Fail 2007;9:440-449.

61. Sauvé MJ, Lewis WR, Blankenbiller M, Rickabaugh B, Pressler SJ. Cognitive impairments in chronic heart failure: a case controlled study. J Card Fail 2009;15:1-10.

62. Huijts M, van Oostenbrugge RJ, Duits A, Burkard T, Muzzarelli S, Maeder MT, et al. Cognitive impairment in heart failure: results from the Trial of Intensified versus standard Medical therapy in Elderly patients with Congestive Heart Failure (TIME-CHF) randomized trial. Eur J Heart Fail 2013;15:699-707.

63. Athilingam $P, D$ 'Aoust RF, Miller L, Chen L. Cognitive profile in persons with systolic and diastolic heart failure. Congest Heart Fail 2013;19:44-50.

64. Zuccalà G, Onder G, Marzetti E, Monaco MR, Cesari M, Cocchi $A$, et al. Use of angiotensin-converting enzyme inhibitors and variations in cognitive performance among patients with heart failure. Eur Heart J 2005;26:226-233.

65. Mohr JP, Albers GW, Amarenco P, Babikian VL, Biller J, Brey RL, et al. Etiology of stroke. Stroke 1997;28:1501-1506.

66. Haeusler KG, Endres M, Doehner W. Relevance of heart failure in prevention, treatment and prognosis of ischemic stroke. Neurol Int Open 2017;1:E61-E64.

67. Lip GY, Gibbs CR. Does heart failure confer a hypercoagulable state? Virchow's triad revisited. J Am Coll Cardiol 1999;33:1424-1426.

68. Di Tullio MR, Qian M, Thompson JL, Labovitz AJ, Mann DL, Sacco $R L$, et al. Left ventricular ejection fraction and risk of stroke and cardiac events in heart failure: data from the warfarin versus aspirin in reduced ejection fraction trial. Stroke 2016;47:2031-2037.

69. Falk RH, Foster E, Coats MH. Ventricular thrombi and thromboembolism in dilated cardiomyopathy: a prospective followup study. Am Heart J 1992;123:136-142.

70. Meltzer RS, Visser CA, Fuster V. Intracardiac thrombi and systemic embolization. Ann Intern Med 1986;104:689-698. 
71. Pullicino PM, Halperin JL, Thompson JL. Stroke in patients with heart failure and reduced left ventricular ejection fraction. Neurology 2000;54:288-294.

72. Wolf PA, Abbott RD, Kannel WB. Atrial fibrillation as an independent risk factor for stroke: the Framingham Study. Stroke 1991;22:983-988.

73. Jug B, Vene N, Salobir BG, Sebestjen M, Sabovic M, Keber I. Procoagulant state in heart failure with preserved left ventricular ejection fraction. Int Heart J 2009;50:591-600.

74. de Peuter OR, Kok WE, Torp-Pedersen C, Büller HR, Kamphuisen PW. Systolic heart failure: a prothrombotic state. Semin Thromb Hemost 2009;35:497-504.

75. Chong AY, Lip GY. Viewpoint: the prothrombotic state in heart failure: a maladaptive inflammatory response? Eur $J$ Heart Fail 2007;9:124-128.

76. Lee KW, Blann AD, Lip GY. Impaired tissue Doppler diastolic function in patients with coronary artery disease: relationship to endothelial damage/dysfunction and platelet activation. Am Heart J 2005;150:756-766.

77. Chin BS, Conway DS, Chung NA, Blann AD, Gibbs CR, Lip GY. Interleukin-6, tissue factor and von Willebrand factor in acute decompensated heart failure: relationship to treatment and prognosis. Blood Coagul Fibrinolysis 2003;14:515-521.

78. Jafri SM, Mammen EF, Masura J, Goldstein S. Effects of warfarin on markers of hypercoagulability in patients with heart failure. Am Heart J 1997;134:27-36.

79. Jafri SM. Hypercoagulability in heart failure. Semin Thromb Hemost 1997;23:543-545.

80. Lip GY, Lowe GD, Metcalfe MJ, Rumley A, Dunn FG. Is diastolic dysfunction associated with thrombogenesis? A study of circulating markers of a prothrombotic state in patients with coronary artery disease. Int J Cardiol 1995;50:31-42.

81. Lip GY, Lowe GD, Metcalfe MJ, Rumley A, Dunn FG. Effects of warfarin therapy on plasma fibrinogen, von Willebrand factor, and fibrin D-dimer in left ventricular dysfunction secondary to coronary artery disease with and without aneurysms. Am J Cardiol 1995;76:453-458.

82. Sbarouni E, Bradshaw A, Andreotti F, Tuddenham E, Oakley $\mathrm{CM}$, Cleland JG. Relationship between hemostatic abnormalities and neuroendocrine activity in heart failure. Am Heart J 1994;127:607-612.

83. Jafri SM, Ozawa T, Mammen E, Levine TB, Johnson C, Goldstein S. Platelet function, thrombin and fibrinolytic activity in patients with heart failure. Eur Heart J 1993;14:205-212.

84. Keber I, Keber D, Stegnar M, Vene N. Tissue plasminogen activator release in chronic venous hypertension due to heart failure. Thromb Haemost 1992;68:321-324.

85. Gibbs CR, Blann AD, Watson RD, Lip GY. Abnormalities of hemorheological, endothelial, and platelet function in patients with chronic heart failure in sinus rhythm: effects of angiotensin-converting enzyme inhibitor and beta-blocker therapy. Circulation 2001;103:1746-1751.

86. Niebauer J, Volk HD, Kemp M, Dominguez M, Schumann RR, Rauchhaus $\mathrm{M}$, et al. Endotoxin and immune activation in chronic heart failure: a prospective cohort study. Lancet 1999;353: 1838-1842.

87. Kubo SH, Rector TS, Bank AJ, Williams RE, Heifetz SM. Endothelium-dependent vasodilation is attenuated in patients with heart failure. Circulation 1991;84:1589-1596.

88. Georgiadis D, Sievert M, Cencetti S, Uhlmann F, Krivokuca M, Zierz $\mathrm{S}$, et al. Cerebrovascular reactivity is impaired in patients with cardiac failure. Eur Heart J 2000;21:407-413.

89. Rajagopalan $B$, Raine $A E_{1}$ Cooper R, Ledingham JG. Changes in cerebral blood flow in patients with severe congestive cardiac failure before and after captopril treatment. Am J Med 1984;76(5B):86-90.

90. Lorenzi-Filho G, Azevedo ER, Parker JD, Bradley TD. Relationship of carbon dioxide tension in arterial blood to pulmonary wedge pressure in heart failure. Eur Respir J 2002;19:37-40.

91. Derdeyn CP, Videen TO, Yundt KD, Fritsch SM, Carpenter DA, Grubb RL, et al. Variability of cerebral blood volume and oxygen extraction: stages of cerebral haemodynamic impairment revisited. Brain 2002;125(Pt 3):595-607.

92. Weber T, Wassertheurer S, O'Rourke MF, Haiden A, Zweiker R, Rammer $M$, et al. Pulsatile hemodynamics in patients with exertional dyspnea: potentially of value in the diagnostic evaluation of suspected heart failure with preserved ejection fraction. J Am Coll Cardiol 2013;61:1874-1883.

93. Vemmos K, Ntaios G, Savvari P, Vemmou AM, Koroboki $E$, Manios $E$, et al. Stroke aetiology and predictors of outcome in patients with heart failure and acute stroke: a 10-year follow-up study. Eur J Heart Fail 2012;14:211-218.

94. He J, Ogden LG, Bazzano LA, Vupputuri S, Loria C, Whelton PK. Risk factors for congestive heart failure in US men and women: NHANES I epidemiologic follow-up study. Arch Intern Med 2001;161:996-1002.

95. Massie BM, Shah NB. Evolving trends in the epidemiologic factors of heart failure: rationale for preventive strategies and comprehensive disease management. Am Heart J 1997;133: 703-712.

96. Kannel WB, Ho K, Thom T. Changing epidemiological features of cardiac failure. Br Heart J 1994;72(2 Suppl):S3-S9.

97. Lee SE, Cho HJ, Lee HY, Yang HM, Choi JO, Jeon ES, et al. A multicentre cohort study of acute heart failure syndromes in Korea: rationale, design, and interim observations of the Korean Acute Heart Failure (KorAHF) registry. Eur J Heart Fail 
2014;16:700-708.

98. Kirchhof P, Benussi S, Kotecha D, Ahlsson A, Atar D, Casadei B, et al. 2016 ESC guidelines for the management of atrial fibrillation developed in collaboration with EACTS. Eur Heart $J$ 2016;37:2893-2962.

99. January CT, Wann LS, Alpert JS, Calkins H, Cigarroa JE, Cleveland JC Jr, et al. 2014 AHA/ACC/HRS guideline for the management of patients with atrial fibrillation: a report of the American College of Cardiology/American Heart Association Task Force on Practice Guidelines and the Heart Rhythm Society. J Am Coll Cardiol 2014;64:e1-e76.

100. Cleland JG, Findlay I, Jafri S, Sutton G, Falk R, Bulpitt C, et al. The Warfarin/Aspirin Study in Heart failure (WASH): a randomized trial comparing antithrombotic strategies for patients with heart failure. Am Heart J 2004;148:157-164.

101. Cokkinos DV, Haralabopoulos GC, Kostis JB, Toutouzas PK; HELAS investigators. Efficacy of antithrombotic therapy in chronic heart failure: the HELAS study. Eur J Heart Fan 2006;8:428-432.

102. Massie BM, Collins JF, Ammon SE, Armstrong PW, Cleland $J G$, Ezekowitz $M$, et al. Randomized trial of warfarin, aspirin, and clopidogrel in patients with chronic heart failure: the Warfarin and Antiplatelet Therapy in Chronic Heart Failure (WATCH) trial. Circulation 2009;119:1616-1624.

103. Homma S, Thompson JL, Pullicino PM, Levin B, Freudenberger $\mathrm{RS}$, Teerlink JR, et al. Warfarin and aspirin in patients with heart failure and sinus rhythm. NEng/ J Med 2012;366:1859-1869.

104. Hopper I, Skiba M, Krum H. Updated meta-analysis on antithrombotic therapy in patients with heart failure and sinus rhythm. Eur J Heart Fail 2013;15:69-78.

105. Kondo T, Yamada T, Morita T, Furukawa Y, Tamaki S, Iwasaki $Y$, et al. The $\mathrm{CHADS}_{2}$ score predicts ischemic stroke in chronic heart failure patients without atrial fibrillation: comparison to other stroke risk scores. Heart Vessels 2017;32:193-200.

106. Melgaard L, Gorst-Rasmussen A, Lane DA, Rasmussen LH, Larsen TB, Lip GY. Assessment of the CHA2DS2-VASc score in predicting ischemic stroke, thromboembolism, and death in patients with heart failure with and without atrial fibrillation. JAMA 2015;314:1030-1038.

107. Melgaard L, Gorst-Rasmussen A, Lip GY, Rasmussen LH, Larsen TB. Female sex is associated with a lower risk of stroke in patients with heart failure. Am Heart J 2015;169:396-403.

108. Batul SA, Gopinathannair R. Atrial fibrillation in heart failure: a therapeutic challenge of our times. Korean Circ J 2017;47:644662.

109. Giugliano RP, Ruff CT, Braunwald E, Murphy SA, Wiviott SD,

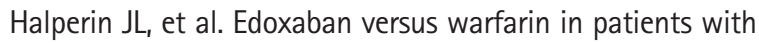
atrial fibrillation. N Engl J Med 2013;369:2093-2104.

110. Patel MR, Mahaffey KW, Garg J, Pan G, Singer DE, Hacke W, et al. Rivaroxaban versus warfarin in nonvalvular atrial fibrillation. N Engl J Med 2011;365:883-891.

111. Granger CB, Alexander JH, McMurray JJ, Lopes RD, Hylek EM, Hanna $M$, et al. Apixaban versus warfarin in patients with atrial fibrillation. N Engl J Med 2011;365:981-992.

112. Connolly SJ, Ezekowitz MD, Yusuf S, Eikelboom J, Oldgren J,

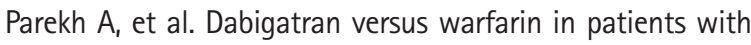
atrial fibrillation. N Engl J Med 2009;361:1139-1151.

113. Ferreira J, Ezekowitz MD, Connolly SJ, Brueckmann M, Fraessdorf M, Reilly PA, et al. Dabigatran compared with warfarin in patients with atrial fibrillation and symptomatic heart failure: a subgroup analysis of the RE-LY trial. Eur J Heart Fail 2013;15:1053-1061.

114. van Diepen $\mathrm{S}$, Hellkamp AS, Patel MR, Becker RC, Breithardt G, Hacke $W$, et al. Efficacy and safety of rivaroxaban in patients with heart failure and nonvalvular atrial fibrillation: insights from ROCKET AF. Circ Heart Fail 2013;6:740-747.

115. Magnani G, Giugliano RP, Ruff CT, Murphy SA, Nordio F, Metra $M$, et al. Efficacy and safety of edoxaban compared with warfarin in patients with atrial fibrillation and heart failure: insights from ENGAGE AF-TIMI 48. Eur J Heart Fail 2016;18:1153-1161.

116. McMurray JJ, Ezekowitz JA, Lewis BS, Gersh BJ, van Diepen $S$, Amerena J, et al. Left ventricular systolic dysfunction, heart failure, and the risk of stroke and systemic embolism in patients with atrial fibrillation: insights from the ARISTOTLE trial. Circ Heart Fail 2013;6:451-460.

117. Isnard R, Bauer F, Cohen-Solal A, Damy T, Donal E, Galinier $M$, et al. Non-vitamin $K$ antagonist oral anticoagulants and heart failure. Arch Cardiovasc Dis 2016;109:641-650.

118. Xiong Q, Lau YC, Senoo K, Lane DA, Hong K, Lip GY. Non-vitamin $\mathrm{K}$ antagonist oral anticoagulants (NOACs) in patients with concomitant atrial fibrillation and heart failure: a systemic review and meta-analysis of randomized trials. Eur J Heart Fail 2015;17:1192-1200.

119. Yeh $\mathrm{CH}$, Hogg K, Weitz Jl. Overview of the new oral anticoagulants: opportunities and challenges. Arterioscler Thromb Vasc Biol 2015;35:1056-1065.

120. Mega JL, Braunwald E, Wiviott SD, Bassand JP, Bhatt DL,

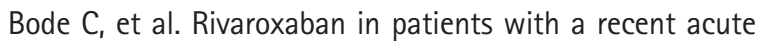
coronary syndrome. N Engl J Med 2012;366:9-19.

121. Zannad F, Greenberg B, Cleland JG, Gheorghiade M, van Veldhuisen DJ, Mehra MR, et al. Rationale and design of a randomized, double-blind, event-driven, multicentre study comparing the efficacy and safety of oral rivaroxaban with placebo for reducing the risk of death, myocardial infarction or stroke in subjects with heart failure and significant coronary artery disease following an exacerbation of heart failure: the COMMANDER HF trial. Eur J Heart Fail 2015;17:735-742. 